\title{
ROLE OF CHEST X-RAY IN TUBERCULOUS CERVICAL LYMPHADENITIS
}

\author{
SHAH R ${ }^{1}$, TALUKDAR DC ${ }^{2}$, FAKIR MAY $^{3}$, HOSSAIN MZ ${ }^{4}$, KHAN AFM $^{5}$, SHAHA PS $^{6}$, KASHEM MA $^{7}$
}

\begin{abstract}
:
Tuberculous cervical lymphadenitis is not an uncommon entity when it comes to otolaryngology practice in Bangladesh. This study was done in the department of ENT and Head Neck Surgery, Dhaka Medical College Hospital, Dhaka, from January 2012 to January 2013 and was designed to find out chest x-ray abnormalities in apparently chest asymptomatic confirmed tuberculous cervical lymphadenitis without associated diseases. The diagnosis of tuberculous cervical lymphadenitis was confirmed by fine needle aspiration cytology (FNAC) and/or smear for acid-fast bacillus, and chest $x$-ray (PA view) was done in all confirmed cases ( $n=183)$. Normal chest $x$-ray was found in 132 cases (72.13\%) and abnormal chest $x$-ray in 51 cases (27.87\%). Pulmonary infiltration, the commonest radiological finding was detected in 32 cases (17.49\%), hilar enlargement in 17 cases (9.29\%), right paratracheal opacity in 2 (1.09\%), obliteration of costophrenic angles in 3 cases (1.64\%) and miliary mottling in one case (0.55\%). Upper zonal predominance of lung parenchymal infiltrations was noted in $12.57 \%$ and right lung involvement in $16.39 \%$. Single zone was affected in $9.84 \%$ cases and multiple zones were involved in $7.65 \%$ cases. We observed right hilar enlargement in $6.56 \%$, left hilar lymphadenopathy in $4.37 \%$ and bilateral hilar lymphadenopathy in $2.73 \%$ cases. We concluded that routine chest $x$-ray should be done in all tuberculous lymphadenitis before categorization and starting of treatment.
\end{abstract}

Key Words: Chest $x$-ray, tuberculosis, cervical lymphadenitis.

J Dhaka Med Coll. 2013; 22(2) : 125-128.

\section{Introduction:}

Lymphadenitis (especially cervical lymphadenitis) is the most common clinical manifestation of extra pulmonary mycobacterial infection ${ }^{1}$. It presents with single / multiple painless lump, mostly located in the posterior cervical or Supraclavicular region ${ }^{2,3}$. Multiplicity, matting and sinus formation are the hallmark of tuberculous lymphadenitis. Tuberculous lymphadenopathy is usually post primary and primary site is usually in the lung. It may be a manifestation of systemic tuberculosis (TB) including pulmonary TB or a unique clinical entity localized to neck. It can result from direct extension or haematogenous spread of infection ${ }^{2}$. Though cervical tuberculous lymphadenitis is common in Bangladesh, there is scarcity of report on lung involvement in tuberculous lymphadenitis, particularly as tuberculosis is very prevalent in Bangladesh. Our objectives of the study were to find out the chest $\mathrm{x}$-ray abnormalities in confirmed cases of tuberculous lymphadenitis, and to find out incidence of associate pulmonary TB.

\section{Material and Methods:}

This study was conducted in Dept of ENT and Head Neck Surgery, Dhaka Medical College Hospital, Dhaka, Bangladesh, a tertiary care hospital draining a large part of patients of the country. All adult patients attending the outpatient department, with confirmed cervical tuberculous lymphadenitis were taken in the study over a period of one year from January 2012 to January 2013. The diagnosis of tuberculous lymphadenitis was confirmed by fine needle aspiration cytology (FNAC) of lymph nodes and demonstration of acid-fast bacilli (AFB) or caseating epithelioid granuloma.

1. Dr. Rameez Shah, Dept of ENT \& Head Neck Surgery, Dhaka Medical College Hospital, Dhaka.

2. Dr. Debesh Chandra Talukdar, Assistant Professor, Dept of ENT \& Head Neck Surgery, Dhaka Medical College, Dhaka.

3. Dr. Md. Abu Yousuf Fakir, Associate Professor, Dept of ENT \& Head Neck Surgery, Dhaka Medical College, Dhaka.

4. Dr. Mohammad Zaid Hossain, Associate Professor, Department of Medicine, Dhaka Medical College

5. Prof. A. F. Mohiuddin Khan, Professor and Head, Dept of ENT \& Head Neck Surgery, Dhaka Medical College, Dhaka.

6. Dr. Partho Sarthi Shaha, Assistant Registrar, Department of Medicine, Dhaka Medical College, Dhaka

7. Dr. Md. Abul Kashem, Assistant Professor, Department of Medicine, Dhaka Medical College, Dhaka

Correspondence: Dr. Rameez Shah, Dept of ENT \& Head Neck Surgery, Dhaka Medical College Hospital, Dhaka, Email: rameezshah527@yahoo.com 
Patients with lymphadenitis in other areas, apparent TB elsewhere or patients having associate medical, surgical or gynaecological disease including HIV infection, diabetes, etc, were excluded from the study. Patients refused to give informed written consent were also excluded. All cases were subjected to detail history, clinical examination and routine blood and biochemistry including sputum examination for AFB. History taking included onset, duration and progression of symptoms, past history of anti-TB drugs, etc. Chest x-ray posterior anterior $(\mathrm{PA})$ view was performed in each case. Chest $\mathrm{x}$-ray findings were classified as normal; pulmonary infiltrate; lymphadenopathy presented as hilar enlargement or paratracheal opacity; cavitations; and pleural effusion presented as obliteration of costophrenic angle. Pulmonary infiltrates were divided according to single or multiple zonal involvement; unilateral or bilateral infiltration; and isolated infiltration or complicated infiltration (with other abnormality).

\section{Results:}

Out of 183 adult patients, 132(72.13\%) were female and $51(27.87 \%)$ male, and 2.59: 1 was the female to male ratio. Ninety-three patients $(50.82 \%)$ were below the age of 30 years of age (Table 1). Single cervical $1 \mathrm{ymph}$ node enlargement was found in 74 cases $(40.44 \%)$ and most of them were in posterior triangle. Multiple lymph node enlargement was noted in 109 cases $(59.56 \%)$, and of them $51.38 \%$ were matted and $41.28 \%$ were non-matted. Sinus formation was found in 25 cases (13.66\%). Lymphadenopathy was left sided in 71 cases $(38.80 \%)$, right sided in 80 cases
$(43.72 \%)$ and bilateral in 32 cases $(17.49 \%)$. FNAC of the gland showed caseating granuloma in 175 cases $(95.63 \%)$. FNAC smears were positive for AFB in 57 cases $(31.15 \%)$ and in 7 cases (3.83\%) FNAC smear was positive for AFB in absence of caseating granuloma. In one case diagnosis was established by excision biopsy and histopathological examination.

Normal CXR was found in 132 cases $(72.13 \%)$ and abnormal CXR was found in 51 cases $(27.87 \%)$ (Table 2). Pulmonary infiltration was the commonest radiological finding, and was found in 32 cases (17.49\%); lymphadenopathy presented as hilar enlargement was found in 17 cases $(9.29 \%)$ and right paratracheal opacity was found in 2 cases (1.09\%) (Fig 1); cavities were found in 3 cases (1.64\%) (Fig 2); pleural effusion presented as obliteration of costophrenic angle was found in 3 cases (1.64\%); and miliary mottling was found in one case $(0.55 \%)$. Distribution of lung infiltrations showed upper zonal prominence, found in 23 cases, followed by mid and lower zonal distributions in 14 and 13 cases respectively. Single zone involvement was found in 18 cases $(9.84 \%)$, two zones were involved in 8 cases $(4.37 \%)$ and three zones were involved in 6 (3.28\%). Right lung was involved in 30 cases $(16.39 \%)$, left lung was involved in 20 cases $(10.93 \%)$ and both lungs were involved in 18 cases $(9.83 \%)$. Complicated infiltration was noted in 5 cases $(2.73 \%)$, and of them 3 had cavities, 1 had pleural effusion and 1 had miliary mottling. Right hilar lymphadenopathy was noted in 12 cases $(6.56 \%)$, left hilar lymphadenopathy was noted in 8 cases $(4.37 \%)$ and bilateral hilar lymphadenopathy was recorded in 5 cases $(2.73 \%)$.

Table-I

Age and Sex wise Distribution of Study Population ( $n=183)$

\begin{tabular}{lccc}
\hline Age in years & \multicolumn{3}{c}{ No of cases $(\%)$} \\
\cline { 2 - 4 } & Male $(\mathrm{n}=51)$ & Female $(\mathrm{n}=132)$ & Total $(\mathrm{n}=183)$ \\
\hline$<15$ & $6(3.28 \%)$ & $24(13.11 \%)$ & $30(16.39 \%)$ \\
$>15$ to 30 & $25(13.66 \%)$ & $68(37.16 \%)$ & $93(50.82 \%)$ \\
$>30$ to 45 & $15(8.20 \%)$ & $32(17.49 \%)$ & $47(25.68 \%)$ \\
$>45$ to 60 & $5(2.73 \%)$ & $6(3.28 \%)$ & $11(6.01 \%)$ \\
$>60$ & 0 & $2(1.09 \%)$ & $02(1.09 \%)$ \\
\hline Total & $51(27.87 \%)$ & $132(72.13 \%)$ & $183(100 \%)$ \\
\hline
\end{tabular}


Table-II

Distribution of Cases according to Radiological Abnormalities in Chest X-ray $(n=183)$

\begin{tabular}{|c|c|c|c|c|c|}
\hline \multirow[t]{2}{*}{ Site and distributionin x-ray } & \multicolumn{5}{|c|}{ X-ray abnormalities $(\mathrm{n}=51 ; 27.87 \%)$} \\
\hline & $\begin{array}{c}\text { Lung } \\
\text { infiltrate } \\
(\mathrm{n}=32 ; 17.49 \%) \\
\end{array}$ & $\begin{array}{l}\text { Lymphadenopathy } \\
\qquad(\mathrm{n}=19 ; 10.38 \%)\end{array}$ & $\begin{array}{c}\text { Pleural } \\
\text { effusion } \\
(\mathrm{n}=3 ; 1.64 \%)\end{array}$ & $\begin{array}{l}\text { Cavitations } \\
(\mathrm{n}=3 ; 1.64 \%) \\
\end{array}$ & $\begin{array}{c}\text { Miliary } \\
\text { mottling } \\
(\mathrm{n}=1 ; 0.55 \%)\end{array}$ \\
\hline \multicolumn{6}{|l|}{ Right lung ( $\mathrm{n}=30 ; 98.75 \%)$} \\
\hline Upper zone & $17(53.13 \%)$ & - & - & - & - \\
\hline Mid zone & $6(18.75 \%)$ & - & - & - & - \\
\hline Lower zone & $7(21.88 \%)$ & - & - & - & - \\
\hline \multicolumn{6}{|l|}{ Left lung ( $n=20 ; 62.05 \%):-$} \\
\hline Upper zone & $6(18.75 \%)$ & - & - & - & - \\
\hline Mid zone & $8(25.00 \%)$ & - & - & - & - \\
\hline Lower zone & $6(18.75 \%)$ & - & - & - & - \\
\hline Both lungs ( $\mathrm{n}=18 ; 56.25 \%)$ & $18(56.25 \%)$ & - & - & - & - \\
\hline $\begin{array}{l}\text { Complicated infiltration } \\
(\mathrm{n}=5 ; 2.73 \%)\end{array}$ & $5(15.63 \%)$ & - & - & - & - \\
\hline \multicolumn{6}{|l|}{ Lymphadenopathy } \\
\hline \multicolumn{6}{|l|}{$(\mathrm{n}=19 ; 10.38 \%):$} \\
\hline Hilar (n=17; 89.47\%) & - & & & & \\
\hline (i) Only right & - & $10(58.82 \%)-$ & - & - & - \\
\hline (ii) Only left & - & 7 (41.18\%)- & - & - & - \\
\hline (iii) Bilateral & - & 5 (29.41\%)- & - & - & - \\
\hline Paratracheal opacity $(n=2 ; 10.5$ & $53 \%)-$ & $2(10.53 \%)-$ & - & - & - \\
\hline Pleural effusion ( $\mathrm{n}=3 ; 1.64 \%)$ & - & - & - & $3(100 \%)$ & - \\
\hline Cavitations $(\mathrm{n}=3 ; 1.64 \%)$ & - & - & - & - & $3(100 \%)$ \\
\hline Miliary mottling $(\mathrm{n}=1 ; 0.55 \%)$ & - & - & - & - & $3(100 \%)$ \\
\hline
\end{tabular}

\section{Discussion:}

The incidence of tuberculous cervical lymphadenitis is increasing in parallel with the increase in the incidence of TB worldwide, and Bangladesh being no exception to it. Cervical lymphadenitis is one of the commonest forms of extra pulmonary TB, where the primary site is usually in the lung. It may be a purely a localized disease or a manifestation of disseminated TB. Tuberculous cervical lymphadenitis is more common in female and found in younger age group. Multiplicity, matting and sinus formation are the hallmark of tuberculous lymphadenopathy, and fistula formation can be seen in almost $10 \%$ of mycobacterial cervical lymphadenitis ${ }^{4}$. Sinus and fistula formation is rare in atypical mycobacterial infection ${ }^{5}$. However, clinical differentiation between them may be misleading. Diagnosis TB cervical lymphadenitis is usually done by FNAC along with AFB smear of the aspirate. FNAC is sensitive, specific and cost-effective way to diagnose mycobacterial cervical lymphadenitis $^{6}$. The sensitivity and specificity of FNAC in the diagnosis of tuberculous lymphadenopathy were found to be $88 \%$ and 96\% respectively ${ }^{7}$.

In the present study, the female to male ratio was 2.59:1, confirming tuberculous cervical lymphadenitis is more common in females. The finding is consistent with other studies, though greater female predominance in this study might be due more female attendance in the 
OPD clinic. In patients with tuberculous cervical lymphadenitis, the abnormalities seen in chest $\mathrm{x}$-ray may be classified into parenchymal, hilar, mediastinal, paratracheal and pleural. In tuberculous cervical lymphadenopathy, the chest x-ray may reveal findings consistent with TB in $14-20 \%$ of the cases ${ }^{8,9}$. In the present study, normal chest $\mathrm{x}$-ray was found in $72.13 \%$ cases and abnormal chest $\mathrm{x}$-ray was noted in $27.87 \%$ patients. Some have reported normal chest x-ray in $47.8 \%{ }^{10}$, parenchymal lesions in $23.2 \%$, and thoracic lymphadenitis in $23.2 \%$ HIV negative patients with cervical tuberculous lymphadenitis. On the other hand, in a recent study $14 \%$ patients showed positive chest $\mathrm{x}$-ray findings suggestive of concurrent pulmonary TB ${ }^{11}$. Less chest $x^{-}$ ray abnormalities noted in this study might be due to exclusion of active pulmonary TB and disseminated TB. We observed lung parenchymal infiltration as commonest form of chest x-ray abnormality, occurring in $62.75 \%$ (32 out of 51 ) patients, and a predominance of upper zonal distribution of lung parenchymal infiltrations in $71.88 \%$ (23 out of 32 ) cases. Zonal distribution of lung infiltrations in tuberculous cervical lymphadenitis was not discussed in any of the previous studies, though it is well known that TB lung infiltration is common in upper zone.

This study confirmed the hypothesis that chest $\mathrm{x}$-ray in apparently chest asymptomatic patients with cervical tuberculous lymphadenopathy might reveal abnormalities consistent with active pulmonary TB. According to prevalent protocol, there is no provision for chest $\mathrm{x}$-ray in extra pulmonary TB and sputum examination is done only for patients having cough, and that might underestimate the coincidence of pulmonary TB. Further study in this regard is necessary to prevent under-treatment in TB lympha- denopathy, especially in Bangladesh, having still many undiagnosed cases of tuberculosis.

\section{References:}

1. Hass DW. Mycobacterium tuberculosis. In: Mandell GL, Bennett JE, Dolin R, eds. Principles and practice of infectious diseases. 5 th ed. Philadelphia: Churchill Livingstone; 2000: p.2576-607.

2. Kankilama M, Mumbuc S, Bayazit Y, Sirikci A. Management strategy of mycobacterial cervical lymphadenitis. J Laryngol Otol 2000; 114 : 274-8.

3. Penfold CN, Reveington PJ. A review of 23 patients with tuberculosis of head and neck. $\mathrm{Br}$ J Oral Maxillofac Surg 1996; 14: 508-10.

4. Konishi K, Yamane H, Iguchi H, Nakagawa T. Study of tuberculosis in the field of otorhinolaryngology in the past 10 years. Acta Otolaryngol Suppl (Stockh) 1998; 598: 244-9.

5. Olson NR. Atypical mycobacterial cervical lymphadenitis: clinical presentation. Laryngoscope 1967; 77: 1376-9.

6. Lau SK, Wei WI, Hsu C, Engzell UC. Fine needle aspiration biopsy of tuberculous cervical lymphadenopathy. Aust N Z J Surg 1988; 58: 947-50.

7. Chao SS, Loh KS, Tan KK, Chong SM. Tuberculous and non-tuberculous cervical lymphadenitis: a clinical review. Otolaryngol Head Neck Surg 2002; 126: $176-9$.

8. Bayazit YA, Bayazit N, Narniduru M. Mycobacterial cervical \lymphadenitis. ORL J Otorhinolaryngol Relat Spec 2004; 66: 275-80.

9. Ibekwe AO, al Shareef Z, al Kindy S. Diagnostic problems of tuberculous cervical adenitis (scrofula). Am J Otolaryngol 1997; 18: 202-5.

10. Rajesekaran S, Gunasekaran M, Jayakumar DD, Jeyaganesh D, Bhanumathi V. Tuberculous cervical lymphadenitis in HIV positive and negative patients. Indian J Tuberc 2001; 48: 201-4.

11. Maharjan H, Hirachan S, Kafle PK, Bista M, Shrestha S, Toran KC, et al. Incidence of tuberculosis in enlarged neck nodes: our experience. Kathmandu Univ Med J 2009; 7 : 54-8. 